\title{
HUBUNGAN KARAKTERISTIK SANTRI DENGAN PERSEPSI MEREKA TENTANG KEMANDIRIAN DI PONDOK PESANTREN
}

\section{RELATIONSHIP BETWEEN SANTRI CHARACTERISTICS WITH THEIR PERCEPTION OF SELF INDEPENDENCY}

\author{
Dwi Purwoko, Amri Jahi, Pang S. Asngari, Darwis S. Gani, dan M. Hisyam.
}

\begin{abstract}
The study analyzed the student's perceptions self autonomi in islamic boarding school. The research aims were (1) to describe santri distribution at spesific observed characteristic, (2) to decsribe santri perception concerning independency, (3) to describe existence of relation between perceptions with several of santri characteristics. The santri included in this research were 487 persons those located around Pesantren in Jakarta, West Java, Central Java, and East Java. There were 13 santri characteristics analyzed in the study: Type of Pesantren, Santri Age, Sex, Duration of Schooling in Pesantren, Santri's Family Background, motivation, intensity in reading books, intensity in interacting with teachers (known as "Kyai"), tribe, distance and condition of pesantren, education background before enrolling, and origin. Independent variables related to the indicators of self autonomy included religion, general knowledge, hope for future, social interaction, discussion in the class, personal management, tolerance, and behavior against the government. Corelation analysis is done by using concordance Kendall W and Kendall Tau showed all of santri characteristics existence of high level agreement in evaluating the independency field.
\end{abstract}

Keywords: Santri Characteristics, Perception, Self Independency.

\section{$\underline{\text { Pendahuluan }}$}

Dalam realitas, santri mencerminkan kehidupan beragama sebagian besar orang Jawa yang taat kepada ajaran Islam. Status ini mengacu kepada salah satu lapisan kesadaran beragama suku Jawa. Katagori ini seringkali berbeda kontras dengan katagori abangan yang mengacu pada kelompok masyarakat Jawa yang kurang taat pada ajaran agamanya. Jadi, perbedaan antara santri dan abangan terjadi bila orang digolongkan dengan mengacu kepada perilaku religiusnya. Dalam kenyataan empiris Jawa, kelompok yang memiliki komitmen tinggi terhadap agama Islam diidentikkan sebagai santri. Seorang santri lebih religius daripada seorang abangan. Namun ukuran religiusnya tentu saja bergantung pada nilai-nilai pribadi orang- orang yang menggunakan istilah tersebut. Dengan demikian, santri merupakan simbol atau identitas keislaman yang kental.

Para santri ada yang berasal dari wong cilik. Pada umumnya santri dari kalangan ini banyak dijumpai di desa-desa, sedangkan di daerah yang lebih bersifat kota terdapat banyak saudagar santri, ada di antara mereka yang memperluas kegiatan ekonominya. Kelompok saudagar ini dapat dianggap sebagai kelas menengah yang berasal bukan dari kalangan bangsawan, tetapi berasal dari kalangan orang desa. Mereka mewarnai dinamika kehidupan masyarakat terutama masyarakat pedesaan di Jawa.

Upaya santri dalam mewarnai kehidupan masyarakat tidak lepas dari personifikasi sikap santri yang taat terhadap 
keagamaan sebagai buah pembelajaran selama di pondok. Artinya, katagori sosial yang dibangun di atas tidak terlepas dari komunitas santri yang ada di pondok.

Salah satu ajaran yang dipegang oleh santri dalam menjalankan agama adalah sikap kemandiriannya. Hal ini telah tampak pada mulanya ketika ia memenuhi kebutuhannya sendiri, mulai dari mencuci pakaian, membersihkan lingkungan, memasak nasi dan sebagainya yang terkait dengan manajemen diri telah dikondisikan selama santri mengalami proses pembelajaran di lingkungan tempat ia menimba ilmu. Praktek semacam ini menjadi bekal bagi mereka kelak ketika terjun di lingkungan masyarakat. Aktivitas keagamaan tampaknya telah menanamkan arti kedisiplinan dan kemandirian bagi diri mereka. Cara hidup semacam ini merupakan cara hidup santri.

Semangat belajar di kalangan santri bukanlah sekedar sebagai kegiatan rutinitas, namun lebih dalam dari maknanya, yaitu yang berkaitan dengan mental manusia, rasa percaya diri, efisiensi waktu, kreativitas, ketabahan, keuletan, kesungguhan, dan moralitas dalam menjalankan usaha secara mandiri yang tujuannnya adalah untuk mempersiapkan santri agar dapat hidup lebih layak sebagai manusia yang kehadirannya ditujukkan untuk mengembangkan dirinya dan masyarakat sekitarnya.

Secara umum tujuan penelitian ini adalah untuk mendeskripsikan adanya hubungan antara karakteristik santri dengan persepsi mereka tentang kemandirian, secara lebih rinci sebagai berikut: (1). Untuk mendeskripsikan distribusi santri pada sejumlah karakteristik yang diamati. (2). Untuk mendeskripsikan persepsi santri tentang kemandirian. (3).Untuk mendeskripsikan adanya hubungan antara persepsi dengan sejumlah karakteristik santri.

\section{Metode Penelitian}

\section{Populasi dan Sampel}

Populasi penelitian ini adalah semua santri yang berada di empat daerah penelitian yakni Jakarta, Jawa Barat, Jawa Tengah dan Jawa Timur.

Jawa Timur dan Jawa Barat juga memiliki banyak pesantren. Darul Ulum Jombang misalnya merupakan pondok pesantren besar yang modern namun di kedua daerah tersebut juga masih memiliki pesantren dengan corak yang tradisional.

Bagian-bagian dari seluruh populasi atau universum disebut sampel. Dan metodologi untuk menyeleksi individuindividu masuk dalam sampel yang representatif disebut sampling (Masri Singarimbun, 1994:88). Responden yang merupakan sampel dari populasi detentukan dengan stratified random sampling. Sampel santri dalam penelitian ini berjumlah 487 santri . Lama penelitian berlangsung dari bulan Februari hingga Agustus 2006.

\section{Analisis Data}

Data hasil penelitian diolah dan ditulis secara analitis. Metode deskriptif analisis data digunakan untuk menganalisis data hasil penelitian. Kemudian dilakukan intepretasi data yang diperoleh baik primer maupun data sekunder dengan bantuan tabel frekuensi. Analisis data memperlihatkan hubungan antar variabel. Dari hasil analisis menunjukkan tingkat kemandirian dari yang rendah, sedang hingga tinggi.

Untuk menganalisis data kuantitatif, khususnya untuk mengetahui ada tidaknya hubungan antar variabel digunakan analisis korelasi Kendall $W$ untuk karakteristik yang terdiri dari tiga kategori dan korelasi Kendall Tau untuk karakteristik yang terdiri dari dua kategori. Data yang terkumpul diolah dengan menggunakan program SPSS (Statistical Package for Social Sciences). Program ini telah lazim digunakan dalam pengolahan data. 
Hasil analisis data dengan alat bantu statistika ini dinilai lebih empiris dalam memecahkan persoalan penelitian (Triton, 2005:13).

Pengumpulan data kualitatif digunakan analisis sebagaimana yang dikemukakan Miles dan Huberman dalam LIPI, 2005, di mana paling tidak ada tiga fase kegiatan dalam melakukan analisa data:
(1) Reduksi data.
(2) Penampilan data.
(3) Penarikan kesimpulan/Verifikasi

\section{Hasil Dan Pembahasan}

\section{Distribusi Karakteristik Santri}

Karakteristik santri yang diamati dalam penelitian ini adalah: (1) Jenis pesantren, (2) Usia, (3) Jenis kelamin (4) Lama pendidikan di pondok, (5) Latar belakang keluarga santri, (6) Motivasi santri, (7) Lingkungan pondok yang meliputi tempat belajar, tempat bermain, tempat ibadah, tempat mengaji, dan tempat istirahat, (8) Intensitas hubungan kyai dan santri, (9) Intensitas membaca, (10) Jarak ke pondok, (11) Pendidikan sebelum mondok, (12) Asal daerah, dan (13) Suku bangsa.

Tabel 1. Distribusi Frekuensi karakteristik Santri

\begin{tabular}{|c|c|c|c|}
\hline Karakteristik & Kategori & Jumlah & Persentase (\%) \\
\hline \multirow{3}{*}{ Jenis Pesantren } & Modern & 145 & 29,77 \\
\hline & Tradisional-Modern & 132 & 27,10 \\
\hline & Tradisional & 210 & 43,12 \\
\hline \multirow{3}{*}{ Usia } & Rendah & 313 & 64,27 \\
\hline & Sedang & 140 & 28,75 \\
\hline & Tinggi & 34 & 6,98 \\
\hline \multirow{2}{*}{ Jenis Kelamin } & Pria & 337 & 69,20 \\
\hline & Wanita & 150 & 30,80 \\
\hline \multirow{3}{*}{ Motivasi } & Agama & 288 & 59,14 \\
\hline & Orang Tua & 58 & 11,91 \\
\hline & Sendiri & 141 & 28,95 \\
\hline \multirow{2}{*}{ Lama Pendidikan Pondok } & Cukup Lama & 300 & 61,60 \\
\hline & Sebentar & 187 & 38,40 \\
\hline \multirow{2}{*}{$\begin{array}{l}\text { Pendidikan Sebelum } \\
\text { Pondok }\end{array}$} & Pendidikan Umum & 326 & 66,94 \\
\hline & Pendidikan Agama & 161 & 33,06 \\
\hline \multirow{3}{*}{ Pekerjaan Orang Tua } & Pegawai Negeri & 123 & 25,26 \\
\hline & Petani & 129 & 26,49 \\
\hline & Swasta & 235 & 48,25 \\
\hline \multirow{3}{*}{ Lama Baca Buku } & Rendah & 311 & 63,86 \\
\hline & Sedang & 115 & 23,61 \\
\hline & Tinggi & 61 & 12,53 \\
\hline \multirow{3}{*}{ Frekuensi Bertemu Kyai } & Jarang & 68 & 13,96 \\
\hline & Biasa Saja & 64 & 13,14 \\
\hline & Sering & 355 & 72,90 \\
\hline \multirow{3}{*}{ Suku Bangsa } & Jawa & 316 & 64,89 \\
\hline & Lainnya & 52 & 10,68 \\
\hline & Sunda & 119 & 24,44 \\
\hline \multirow{2}{*}{ Asal Daerah } & Jawa & 417 & 85,63 \\
\hline & Luar Jawa & 70 & 14,37 \\
\hline
\end{tabular}


Lanjutan Tabel 1. Distribusi Frekuensi karakteristik Santri

\begin{tabular}{|l|l|c|c|}
\hline Karakteristik & Kategori & Jumlah & Persentase (\%) \\
\hline \multirow{3}{*}{ Tempat Belajar } & Buruk & 29 & 5,95 \\
\cline { 2 - 4 } & Cukup & 51 & 10,47 \\
\cline { 2 - 4 } & Baik & 407 & 83,57 \\
\hline \multirow{3}{*}{ Tempat Bermain } & Buruk & 29 & 5,95 \\
\cline { 2 - 4 } & Cukup & 51 & 10,47 \\
\cline { 2 - 4 } & Baik & 407 & 83,57 \\
\hline \multirow{3}{*}{ Tempat Mengaji } & Buruk & 7 & 1,44 \\
\cline { 2 - 4 } & Cukup & 15 & 3,08 \\
\cline { 2 - 4 } & Baik & 465 & 95,48 \\
\hline \multirow{3}{*}{ Tempat Istirahat } & Buruk & 8 & 1,64 \\
\cline { 2 - 4 } & Cukup & 466 & 2,67 \\
\cline { 2 - 4 } & Baik & 16 & 95,69 \\
\hline \multirow{2}{*}{ Jarak ke Pondok } & Buruk & 39 & 8,29 \\
\cline { 2 - 4 } & Cukup & 306 & 88,71 \\
\cline { 2 - 4 } & Baik & 181 & 62,83 \\
\cline { 2 - 4 } & Dekat & Jauh & 37,17 \\
\hline
\end{tabular}

Tabel di atas menunjukkan bahwa dari keseluruhan santri Pondok pesantren yang dijadikan sampel, sebagian besar santri berusia muda atau rendah yaitu di bawah 19 tahun, lebih dari setengah santri adalah lakilaki, motivasi masuk pondok karena agama, belajar di pondok cukup lama yaitu lebih dari 5 tahun, pendidikan sebelum mondok adalah pendidikan umum, pekerjaan orang tua sebagian besar santri adalah swasta, intensitas membaca buku adalah masih rendah yaitu kurang dari 5 jam, intensitas bertemu kyai adalah sering, sebagian santri berasal dari Jawa suku Jawa, jarak rumah santri ke pondok adalah dekat yaitu kurang dari 1,7 $\mathrm{Km}$, dan lingkungan pondok yang meliputi tempat belajar, tempat bermain, tempat ibadah, tempat mengaji, dan tempat istirahat kondisinya adalah baik.

\section{Tingkat Kemandirian Santri Di Pondok Pesantren}

Hasil penelitian tentang kemandirian santri di Pondok Pesantren dapat diuraikan pada tabel tabel 2 .

Tabel 2 menunjukkan bahwa kemandirian santri di Pondok Pesantren terbagi dalam delapan bidang yaitu belajar memperdalam pengetahuan umum, belajar menggali pengetahuan agama, harapan/orientasi, manajemen diri, interaksi sosial, diskusi dalam kelas, dan toleransi, dan sikap pada pemerintah. Dari delapan bidang kemandirian tersebut, lima bidang kemandirian yang dianggap paling tinggi adalah Kesadaran belajar mandiri, Kognitif agama tentang kemandirian, percaya diri, harapan untuk mandiri, dan teguh berpendirian. Sedangkan tiga bidang yang dianggap masih rendah adalah manajemen diri, membantu orang lain, dan menolong diri sendiri. 
Tabel 2. Kemandirian Santri di Pondok Pesantren

\begin{tabular}{|l|c|c|}
\hline \multicolumn{1}{|c|}{ Bidang-Bidang Kemandirian } & $\begin{array}{c}\text { Skor } \\
\text { Tertimbang }\end{array}$ & Jenjang \\
\hline Kesadaran Belajar Mandiri & 4,548 & 1 \\
\hline Kognitif Agama Tentang Kemandirian & 4,486 & 2 \\
\hline Percaya Diri & 4,364 & 3 \\
\hline Harapan Untuk Mandiri & 4,354 & 4 \\
\hline Teguh Berpendirian & 4,225 & 5 \\
\hline Manajemen Diri & 4,125 & 6 \\
\hline Membantu Orang lain & 3,840 & 7 \\
\hline Menolong Diri Sendiri & 3,738 & 8 \\
\hline
\end{tabular}

\section{Hubungan Karakteristik Santri dengan \\ Kemandirian di Pondok Pesantren}

Hubungan karakteristik santri dengan kemandirian di pondok pesantren disajikan pada tabel 3 .

Tabel 3 memperlihatkan bahwa hampir keseluruhan karakteristik santri memiliki hubungan yang signifikan dengan kemandirian santri di Pondok Pesantren.

Tabel 3. Hubungan Karakteristik Santri dengan Kemandirian di Pondok

\begin{tabular}{|c|l|c|}
\hline No. & \multicolumn{1}{|c|}{ Karakteristik Santri } & $\begin{array}{c}\text { Koefisien Kendall } \boldsymbol{W} \\
\text { Bidang Kemandirian }\end{array}$ \\
\hline 1 & Jenis Pondok Pesantren & $0,968^{* *}$ \\
\hline 2 & Usia & $0,968^{* *}$ \\
\hline 3 & Motivasi Masuk Pondok & $0,989^{* *}$ \\
\hline 4 & Pekerjaan Orang Tua & $0,979^{* *}$ \\
\hline 5 & Lama Membaca Buku & $0,989^{* *}$ \\
\hline 6 & Tempat Belajar & $0,873^{*}$ \\
\hline 7 & Tempat Bermain & $0,937^{* *}$ \\
\hline 8 & Tempat Ibadah & $0,868^{*}$ \\
\hline 9 & Tempat Mengaji & $0,884^{*}$ \\
\hline 10 & Tempat Istirahat & $0,857^{*}$ \\
\hline 11 & Intensitas Bertemu Kyai & $0,912^{* *}$ \\
\hline 12 & Suku Bangsa & $0,979^{* *}$ \\
\hline
\end{tabular}

Keterangan : ** nyata pada $\alpha=0,01$

* nyata pada $\alpha=0,05$ 
Dari Tabel 3 juga dapat diketahui bahwa terdapat tingkat keseragaman atau kesepakatan yang tinggi pada kategori masing-masing karakteristik santri terhadap delapan bidang kemandirian santri di Pondok Pesantren.

Dari keseluruhan karakteristik santri yang mempunyai hubungan yang sangat nyata pada $\alpha$ sebesar 0,01 dan tingkat kesepakatan yang tinggi dengan kemandirian santri di
Pondok Pesantren adalah jenis pondok pesantren, usia santri, pekerjaan orang tua santri, tempat bermain, intensitas bertemu dengan kyai, dan suku bangsa santri.

Karakteristik santri yang mempunyai hubungan nyata pada $\alpha$ sebesar 0,05 dan mempunyai kesepakatan yang tinggi dalam menilai delapan bidang kemandirian adalah tempat belajar, tempat ibadah, tempat mengaji, dan tempat istirahat.

Tabel 4. Hubungan Karakteristik Santri

dengan Kemandirian di Pondok menggunakan analisis Kendall Tau

\begin{tabular}{|r|l|c|}
\hline No. & \multicolumn{1}{|c|}{ Karakteristik Santri } & $\begin{array}{c}\text { Nilai Konkordansi Kendall } \\
\text { Tau } \\
\text { Bidang Kemandirian }\end{array}$ \\
\hline 1 & Jenis Kelamin & $0,857^{* *}$ \\
\hline 2 & Lama Mondok & $0,929^{* *}$ \\
\hline 3 & Pendidikan Sebelum Pondok & $0,929^{* *}$ \\
\hline 4 & Jarak Rumah ke Pondok & $0,929^{* *}$ \\
\hline 5 & Asal Daerah & $0,929^{* *}$ \\
\hline
\end{tabular}

Keterangan : ** nyata pada $\alpha=0,01$

* nyata pada $\alpha=0,05$

Tabel 4 di atas menunjukkan bahwa karakteristik santri seperti jenis kelamin, lama mondok, pendidikan sebelum pondok, dan asal daerah mempunyai hubungan yang signifikan pada taraf dengan $\alpha$ sebesar 0,01 dengan kemandirian santri di pondok pesantren.

\section{$\underline{\text { Kesimpulan }}$}

1. Sebagian besar santri pondok pesantren merupakan: kelompok umur muda (rendah), jenis kelamin pria, motivasi masuk agama karena agama, cukup lama belajar di pondok, pendidikan sebelum pondok pendidikan umum, pekerjaan orang tua adalah swasta, intensitas membaca buku adalah masih rendah, intensitas bertemu kyai sering, berasal dari Jawa dengan suku bangsa Jawa, jarak rumah santri ke pondok adalah dekat, dan lingkungan pondok yang meliputi tempat belajar, tempat bermain, tempat ibadah, tempat mengaji, dan tempat istirahat kondisinya adalah baik.

2. Kamandirian santri di pondok pesantren yang masih rendah dapat dinyatakan secara berurutan sebagai berikut: (1) Manajemen diri, (2) Membantu orang lain, (3) Menolong diri sendiri.

3. Analisis hubungan karakteristik santri dengan kemandirian santri di pondok menunjukkan bahwa hampir keseluruhan karakteristik santri memperlihatkan terdapat kesepakatan yang tinggi dalam menilai kedelapan bidang kemandirian santri.

\section{Rujukan}

Amri Jahi. 1983. Komunikasi Pembangunan di Negara Dunia Ketiga. Jakarta: Gramedia. 
Amri Jahi. et. al (Penyunting), 2004. Pengembangan Masyarakat Mandiri: Ilmu Penyuluhan Pembangunan Meningkatkan Kapasitas SDM Menuju Kemandiran, PPN kerjasama dengan Departemen Pertanian RI, Bogor.

Anonim, 1998. Sejarah Pondok Pesantren Tarbiyatun Nasyiin Pacul Gowang. tp, Jombang.

Apps, Jerold W. 1993. Toward a Working Philosophy of Adult Education, Syracus University.

Asngari, Pang S. 1984. "Persepsi Direktur Penyuluhan Tingkat "Karesidenan" dan Kepala Penyuluh Pertanian terhadap Peranan dan Fungsi Lembaga Penyuluhan Pertanian di Negara Bagian Texas Amerika Serikat," Media Peternakan, Vol.9.

Broom , Leonard. 1963. Sociology: A Text with Adapted Readings. New York: Harper and Row Publishers.

Dhofier, Zamaksari. $1996 . \quad$ Tradisi Pesantren. Jakarta : LP3ES.

Donnelly, Jack. 1989. Universal Human Rights in Theory and Practice. USA: Cornell University Press.

Geertz, C. 1983. Abangan, Santri, Priyayi Dalam Masyarakat Jawa. Terjemahan, YIIS, cet. Kedua. Jakarta: Pustaka Jaya.

Gibson, Alvin A. 1985. Group Communication, Discussion Process and Aplication (terj.). Jakarta: UI Press.

Jalaluddin Rakhmat. 1985. Psikologi Komunikasi. Bandung: Remadja Karya.

Kamath, M.G., 1961. Tension Education in Community Development. New Delhi: Directorate of Extension.

Lauer, Robert H., P,2001. Perspektif tentang Perubahan Sosial, Jakarta: Rineka Cipta.
Loomis, Charles P. 1967. Social Systems: Essays on Their Persistence and Change. D. van Nostrand Company, New Jersey: Inc. Princeton.

LIPI , 2000. Pengembangan Motivasi dan Potensi Wirausaha Masyarakat. Jakarta: LIPI.

Marcel, Gabriel. 2005. Misteri Eksistensi: Menyelami Makna Keberadaan. Yogyakarta: Kreasi Wacana.

Mastuhu, 1989. Dinamika Sistem Pendidikan Pesantren: Suatu Kajian Tentang Unsur dan Nilai Sistem Pendidikan Pesantren: Disertasi. Bogor: Fakultas Pascasarjana Institut Pertanian Bogor.

Misra,R.P. and M. Honjo, 1981. Changing Perception of Development Problems, Maruzen Asia, Japan.

van Peursen, C.A. 1983. Orientasi di Alam Filsafat. Jakarta: Gramedia.

Rogers, Carl R. 1961. On Becoming a Person: A Therapist's View of Psychothreapy. Boston: Houghton Mifflin Company.

Sidogiri.com. Sidogiri: Ikon Ekonomi Syariah di Pesantre. Tersedia pada http://www.sidogiri.com/modules.php?n ame-News diakses tanggal 17 Januari 2006. Internet.

Tubagus Hasanuddin. 2004.”Dinamika Organisasi Pesantren di Propinsi Jawa Barat : Kasus Pada Enam Pesantren Jawa Barat" Disertasi. Bogor: Sekolah Pasca Sarjana IPB Bogor.

UGM. Seminar Mewujudkan Indonesia Pasti: Strategi Menuju Kemandirian Bangsa tersedia pada http://www.ugm.ac.id/ index.php?page-rillisdanartikel-14, diakses 6 Oktober 2005. Internet.

Taufik Ismail, dkk. 2000. Kemandirian Pesantren Darul Falah. Bogor: Darul Falah.

Wolf, Thomas, 1990. Managing a Nonprofit Organization. London: Prentice Hall Press.

Ziemek, Manfred. 1986. Pesantren Dalam Perubahan Sosial. Jakarta: P3M. 